Table 1. Interstitial lung disease in PsA vs. RA in five Nordic biologic registers

\begin{tabular}{|c|c|c|c|c|c|c|c|c|c|c|}
\hline & \multicolumn{2}{|c|}{ DENMARK } & \multicolumn{2}{|c|}{ FINLAND } & \multicolumn{2}{|c|}{ ICELAND } & \multicolumn{2}{|c|}{ NORWAY } & \multicolumn{2}{|c|}{ SWEDEN } \\
\hline & RA & PsA & RA & PsA & RA & PsA & RA & PsA & RA & PsA \\
\hline $\begin{array}{l}\text { Number of } \\
\text { individuals }\end{array}$ & 7829 & 3386 & 4946 & 1091 & 675 & 470 & 1590 & 999 & 20596 & 6393 \\
\hline $\begin{array}{l}\text { Number of } \\
\text { treatment } \\
\text { courses }\end{array}$ & 17072 & 6640 & 8634 & 1845 & 1280 & 859 & 2379 & 1427 & 38279 & 10824 \\
\hline $\begin{array}{l}\text { Age baseline } \\
\text { (SD) }\end{array}$ & $\begin{array}{c}57.3 \\
(13.1)\end{array}$ & $\begin{array}{c}49.0 \\
(12.6)\end{array}$ & $\begin{array}{c}53.8 \\
(13.4)\end{array}$ & $\begin{array}{c}48.8 \\
(11.4)\end{array}$ & $\begin{array}{c}53.9 \\
(14.2)\end{array}$ & $\begin{array}{c}50.1 \\
(13.3)\end{array}$ & $\begin{array}{l}53.8 \\
(13.7)\end{array}$ & $\begin{array}{c}48.7 \\
(12.0)\end{array}$ & $\begin{array}{c}57.1 \\
(13.7)\end{array}$ & $\begin{array}{c}50.6 \\
(12.8)\end{array}$ \\
\hline Female n (\%) & $\begin{array}{c}12963 \\
(76)\end{array}$ & $\begin{array}{c}3929 \\
(59)\end{array}$ & $\begin{array}{l}6571 \\
(76)\end{array}$ & $\begin{array}{l}933 \\
(51)\end{array}$ & $\begin{array}{l}969 \\
(76)\end{array}$ & $\begin{array}{l}551 \\
(65)\end{array}$ & $\begin{array}{l}1815 \\
(77)\end{array}$ & $\begin{array}{l}818 \\
(57)\end{array}$ & $\begin{array}{c}29635 \\
(77)\end{array}$ & $\begin{array}{c}6162 \\
(57)\end{array}$ \\
\hline $\begin{array}{l}\text { Number of } \\
\text { PYR }\end{array}$ & 40235 & 13986 & 21798 & 4910 & 4517 & 2799 & 4556 & 2653 & 120334 & 27412 \\
\hline $\begin{array}{l}\text { ILD-events } \\
\text { within PYR }\end{array}$ & 218 & 22 & 132 & 8 & 7 & 2 & 32 & 6 & 680 & 28 \\
\hline IR pr 1000 PYR & 5.4 & 1.6 & 6.1 & 1.6 & 1.5 & 0.7 & 7.0 & 2.3 & 5.7 & 1.0 \\
\hline $\begin{array}{l}\text { IRR PsA vs } \\
\text { RA crude }\end{array}$ & \multicolumn{2}{|c|}{0.29} & 0.27 & $\begin{array}{l}27 \\
0.55)\end{array}$ & & $\begin{array}{l}46 \\
-2.42)\end{array}$ & 0.32 & $\begin{array}{l}32 \\
0.78)\end{array}$ & $\begin{array}{r}0.1 \\
(0.12-\end{array}$ & $\begin{array}{l}18 \\
0.26)\end{array}$ \\
\hline HR PsA vs RA & \multicolumn{2}{|c|}{$\begin{array}{c}0.31 \\
(0.17-0.56)\end{array}$} & \multicolumn{2}{|c|}{$\begin{array}{c}0.46 \\
(0.22-0.96)\end{array}$} & \multicolumn{2}{|c|}{$\begin{array}{c}0.62 \\
(0.12-3.14)\end{array}$} & \multicolumn{2}{|c|}{$\begin{array}{c}0.19 \\
(0.06-0.54)\end{array}$} & \multicolumn{2}{|c|}{$\begin{array}{c}0.25 \\
(0.17-0.37)\end{array}$} \\
\hline
\end{tabular}

PYR: Patient years at risk, IR: Incidence rates, IRR: Incidence rate ratios, HR: Hazard Ratios

Conclusion: In these preliminary analyses, the incidence of ILD is lower in bDMARD treated PsA vs. RA patients, irrespective of co-medication with MTX. This indicates that the clinician should consider the rheumatological diagnosis when assessing the risk for future ILD in patients treated with bDMARDs and MTX. Acknowledgements: Partly funded by NordForsk and FOREUM

Disclosure of Interests: Sella Aarrestad Provan Consultant of: Novartis, Grant/ research support from: Boehringer-Ingelheim, Brigitte Michelsen: None declared, Lotta Ljung: None declared, Thorarinn Jonmundsson: None declared, Björn Gudbjornsson Speakers bureau: Amgen and Novartis, Daniela Di Giuseppe: None declared, Merete Lund Hetland Speakers bureau: Orion Pharma, Biogen, Pfizer, CellTrion, Merck and Samsung Bioepis, Consultant of: Eli Lilly, Grant/research support from: BMS, MSD, AbbVie, Roche, Novartis, Biogen and Pfizer, Guðrún Björk Reynisdóttir: None declared, Bente Glintborg: None declared, Eirik kristianslund: None declared, Heikki Relas: None declared, Kalle Aaltonen: None declared, Dan Nordström Speakers bureau: Abbvie, BMS, Celgene, Eli Lilly, MSD, Novartis, Pfizer, Roche and UCB., Consultant of: Abbvie, BMS, Celgene, Eli Lilly, MSD, Novartis, Pfizer, Roche and UCB., Tore K. Kvien Speakers bureau: Amgen, Celltrion, Egis, Evapharma, Ewopharma, Hikma, Oktal, Sandoz, Sanofi., Consultant of: AbbVie, Amgren, Biogen, Celltrion, Eli Lilly, Gilead, Mylan, Novartis, Pfizer, Roche, Sandoz, Sanofi., Johan Askling Grant/research support from: Abbvie, BMS, Eli Lilly, Merck, Pfizer, Roche, Samsung Bioepis, and Sanofi DOI: 10.1136/annrheumdis-2021-eular.2955

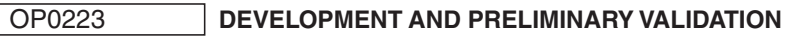 OF ULTRASONOGRAPHIC DISEASE ACTIVITY AND DAMAGE SCORES IN PSORIATIC ARTHRITIS PATIENTS: RESULTS FROM THE UPSTREAM (ULTRASOUND IN PSORIATIC ARTHRITIS TREATMENT) STUDY}

A. Zabotti ${ }^{1}$, M. Piga ${ }^{2}$, A. Zanetti ${ }^{3}$, M. Canzoni ${ }^{4}$, N. Boffini ${ }^{5}$, V. Picerno ${ }^{6}$, G. Zanframundo ${ }^{7}$, E. Silvagni ${ }^{8}$, I. Giovannini ${ }^{1}$, B. Raffeiner ${ }^{9}$, P. Scolieri ${ }^{10}$, P. Mancini ${ }^{11}$, S. Parisi ${ }^{12}$, A. Bortoluzzi ${ }^{8}$, G. Sakellariou ${ }^{13}$, O. De Lucia ${ }^{14}$, I. Tinazzi ${ }^{15}$, F. Figus $^{16}$, L. Idolazzi ${ }^{17}$, M. Lorenzin ${ }^{18}$, S. Z. Callegher ${ }^{1}$, A. Cauli ${ }^{19}$ G. Carrara ${ }^{3}$, C. A. Scirè ${ }^{3}, A$. lagnocco ${ }^{16}$, on behalf of The Musculoskeletal Ultrasound Study Group of the Italian Society of Rheumatology. ${ }^{1}$ University of Udine, Rheumatology Clinic, Santa Maria della Misericordia Hospital, Medical and Biological Sciences Department, Udine, Italy; ${ }^{2}$ Rheumatology Unit, AOU and University of Cagliari, Department of Medical Sciences and Public Health, Monserrato, Italy; ${ }^{3}$ Italian Society for Rheumatology, Epidemiology Research Unit, Milano, Italy; ${ }^{4}$ Local Health Unit (ASL) Rome-1, Rome-4 and Viterbo, Rheumatologist Outpatient Specialist, Rome, Italy; ${ }^{5}$ IRCCS Ospedale S. Raffaele, UNIRAR Department, Milano, Italy; ${ }^{6}$ Azienda Ospedaliera San Carlo, Dipartimento internistico, Potenza, Italy; ${ }^{7}$ Pavia, Department of Internal Medicine and Therapeutics, Pavia, Italy; ${ }^{8}$ University of Ferrara, Department of Medical Sciences, Cona, Italy; ${ }^{9}$ Central Hospital of Bolzano, Rheumatology Unit, Bolzano, Italy; ${ }^{10}$ Ospedale Nuovo Regina Margherita, Dipartimento delle Specialità Mediche, Rome, Italy; ${ }^{11}$ Ospedale S. Spirito e Nuovo Regina Margherita, U.O.C. Radiologia, Rome, Italy; ${ }^{12}$ AOU Città della Salute e della Scienza di Torino, Rheumatology Unit, Turin, Italy; ${ }^{13}$ Scientific Clinical Institutes Maugeri IRCCS, Department of General Medicine, Pavia, Italy; ${ }^{14}$ ASST Centro Ortopedico Traumatologico G. Pini-CTO, Dipartimento di reumatologia e scienze mediche, Milano, Italy; ${ }^{15}$ Ospedale Sacro Cuore di Negrar, UOS di Reumatologia, Negrar di Valpolicella, Italy; ${ }^{16}$ Academic Rheumatology Centre,
Dipartimento Scienze Cliniche e Biologiche, Turin, Italy; ${ }^{17}$ University of Verona, Department of Medicine, Verona, Italy; ${ }^{18}$ Padua, Department of Medicine DIMED, Padua, Italy; ${ }^{19}$ Rheumatology Unit, Medical Sciences and Public Health, University of Cagliari, Cagliari, Italy

Background: The UPSTREAM (NCT03330769) is a 24-month multi-center prospective cohort study that primarily aims to evaluate the additional value of musculoskeletal ultrasound (msk-US) over clinical examination in predicting 6-month minimal disease activity in Psoriatic Arthritis (PsA). (1)

Objectives: To develop and preliminarily validate an activity msk-US score and a damage msk-US score for PsA using the UPSTREAM database.

Methods: Patients classified with PsA according to CASPAR criteria and starting a new course of therapy for clinically active peripheral joint disease were eligible. The information regarding objectives, study design, clinical and US assessment has already been published (1). The msk-US examination was performed in 42 joints, 36 tendons, 12 entheses and 2 bursae defined through a web-based exercise (2). The sonographic elementary lesions were allocated to disease activity [i.e. synovitis (sy), tenosynovitis (ts), peritendinitis (pt), bursitis (bs) all evaluated both in Grey Scale (GS) and Power Doppler (PD) and active enthesitis (en)] and to damage (i.e. joint erosion, bone proliferation, tendon tear, enthesophyte, calcification and irregular enthesis bone profile). Hands and feet X-ray were assessed using the modified Sharp-Van der Heijde (mSVH) score. A principal component (PC) analysis (PCA) was performed for each score and the number of PCs was defined by means of parallel analysis using baseline data. Each PC was normalized $(n)$ taking into account the proportion between the observed value (e.g. sy-GS count) and the maximum expected value (e.g. 42 for sy-GS). Spearman' correlation was used to investigate the construct and discrimination validity of the new scores.

Results: Between February 2017 and May 2020, 312 PsA patients (155 men), with a mean (SD) age of 52.8 13.4, were enrolled from 19 centers; 22 expert sonographers were involved with substantial agreement for US lesions evaluated $(k \geq 0.7)$. The median [IQR] disease duration was 1.3 [0.1-6.1] years and the median [IQR] tender joint and swollen joint counts were 6 [3-13] and 2 [1-5], respectively. The weight derived from PCA for each sonographic lesions and the final equation for calculating the scores are reported in Figure 1 ( $1 \mathrm{~A}$ activity and $1 B$ damage). The final msk-US activity score [n(ts-GS + ts-PD)*2.87] $+\left[\mathrm{n}(\mathrm{bs}-\mathrm{GS}+\mathrm{bs}-\mathrm{PD})^{\star} 1.76\right]+\left[\mathrm{n}(\mathrm{pt}-\mathrm{GS}+\mathrm{pt}-\mathrm{PD})^{\star} 1.43\right]+\left[\mathrm{n}(\text { active en })^{\star} 1.00\right]+$ [n(sy-GS)*0.83] + [n(sy-PD)*0.45] has the best construct and discrimination validities according to a significant correlation with all clinical variables usually related to clinical activity (Table 1). The msk-US damage score correlated with $\mathrm{mSVH}$ score, HAQ and other clinical variables (Table 1).

Table 1.

\begin{tabular}{lcccc}
\hline & \multicolumn{2}{c}{ Msk-US activity score } & \multicolumn{2}{c}{ Msk-US damage score } \\
\cline { 2 - 5 } & $\begin{array}{c}\text { Spearman } \\
\text { correlation }\end{array}$ & $P$-value & $\begin{array}{c}\text { Spearman } \\
\text { correlation }\end{array}$ & $P$-value \\
Variables & 0.196 & 0.002 & 0.075 & 0.235 \\
\hline ESR & 0.209 & $<0.001$ & 0.068 & 0.254 \\
CRP & 0.338 & $<0.001$ & 0.286 & $<0.001$ \\
TJC & 0.338 & $<0.001$ & 0.072 & 0.221 \\
SJC & 0.284 & $<0.001$ & -0.061 & 0.306 \\
Dactylitis count & 0.194 & 0.001 & 0.214 & $<0.001$ \\
LEI & 0.15 & 0.012 & 0.016 & 0.793 \\
Physician GA & 0.138 & 0.018 & -0.073 & 0.221 \\
Patient GA activity & 0.199 & 0.001 & -0.027 & 0.648 \\
Patient GA pain & 0.238 & $<0.001$ & 0.146 & 0.014 \\
HAQ & 0.237 & $<0.001$ & 0.175 & 0.003 \\
BASDAI & 0.7 & 0.004 & 0.148 & 0.013 \\
PSAID-9 & 0.392 & $<0.001$ & 0.228 & $<0.001$ \\
DAPSA & 0.115 & 0.2 & 0.266 & 0.003 \\
Sharp van Der Heijde score & & & & \\
\hline
\end{tabular}

A

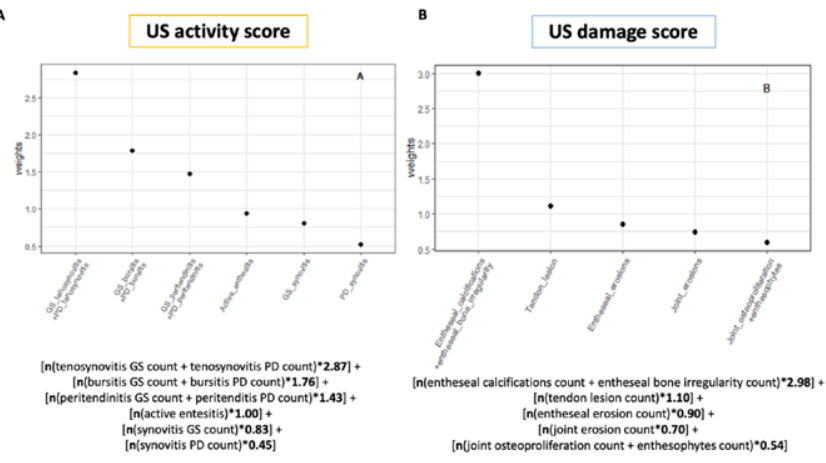

Figure 1. 
Conclusion: These newly developed and preliminary validated msk-US activity and damage scores could be used in patients with PSA in the context of observational and controlled trials.

REFERENCES:

[1] Canzoni M et al. BMJ Open. 2018;8:e021942.

[2] Zabotti A et al. Ann Rheum Dis 2018;77:1537-1538.

Acknowledgements: Alberto Batticciotto; Oscar Massimiliano Epis; Luisa Arcarese; Luca Navarini; Marta Caprioli; Mirco Magnani; Roberta Ramonda; Marco Amedeo Cimmino

Disclosure of Interests: Alen Zabotti: None declared, Matteo Piga: None declared, Anna Zanetti: None declared, Marco Canzoni: None declared, nicola boffini: None declared, valentina picerno: None declared, Giovanni Zanframundo: None declared, Ettore Silvagni: None declared, Ivan Giovannini: None declared, BERND RAFFEINER: None declared, Palma Scolieri: None declared, Paola Mancini: None declared, Simone Parisi: None declared, Alessandra Bortoluzzi Grant/research support from: GSK, Garifallia Sakellariou Consultant of: Consultant for Abbvie and Novartis, Orazio De Lucia: None declared, Ilaria Tinazzi: None declared, Fabiana Figus: None declared, Luca Idolazzi Speakers bureau: Received grants as speaker for Eli Lilly, UCB, Celgene, MSD, Abbvie, Novartis, Paid instructor for: Paid instructor for UCB during Product specialist Meeting, Mariagrazia Lorenzin: None declared, Sara Zandonella Callegher: None declared, Alberto Cauli: None declared, Greta Carrara: None declared, Carlo Alberto Scirè: None declared, Annamaria lagnocco: None declared DOI: 10.1136/annrheumdis-2021-eular.2609

\section{OP0224 CONTINUOUS COMPOSITE MEASURES FOR ROUTINE CARE IN PSORIATIC ARTHRITIS: THRESHOLDS OF MEANING AND CLINICALLY IMPORTANT DIFFERENCE ESTIMATES FOR THE 3 AND 4 VAS SCALES FROM A UK MULTICENTRE STUDY}

W. Tillett ${ }^{1,2}$, J. Day $^{1}$, N. Mchugh ${ }^{2}$, O. Fitzgerald ${ }^{3}$, L. C. Coates ${ }^{4}$, P. Helliwell ${ }^{5}$. ${ }^{1}$ Royal National Hospital for Rheumatic Diseases, Rheumatology, Bath, United Kingdom; ${ }^{2}$ University of Bath, Pharmacy and Pharmacology, Bath, United Kingdom; ${ }^{3}$ University College Dublin, Conway Institute for Biomolecular Research, Dublin, Ireland; ${ }^{4}$ University of Oxford, Nuffield Department of Orthopaedics, Oxford, United Kingdom; ${ }^{5}$ University of Leeds, Leeds Institute of Rheumatic and Musculoskeletal Medicine, Leeds, United Kingdom

Background: There is a recognised need for a continuous composite measure of disease activity for the assessment of Psoriatic Arthritis (PsA) in routine clinical settings to allow objective assessment of response and implementation of treat to target. ${ }^{1}$ Longer multidimensional measures are considered less feasible in routine care and a number of shorter measures have been proposed including, the Disease Activity Score for Psoriatic Arthritis (DAPSA), Disease Activity Score 28 (DAS28), the 3 Visual Analogue Scale (VAS) (comprising physician global VAS, patient global VAS and patient skin VAS) or 4 VAS (comprising physician global VAS, patient pain VAS, joint VAS and patient skin VAS). Testing of these measures in clinical trial datasets has been suggested but thresholds of meaning have not been established. ${ }^{2}$

Objectives: To estimate clinically relevant thresholds of disease activity and improvement for composite measures for routine clinical practice in PsA.

Methods: Clinical and patient reported outcome measures were assessed in patients fulfilling CASPAR criteria for PsA at three consecutive follow up visits in a UK multicentre observational study. Participants underwent clinical assessment and completed patient reported measures including health anchor questions. Estimates for Minimal Detectible Change (MDC) were derived using $1.96^{\star} 2^{\star}$ Standard Error of the Mean (SEM). Minimal Clinically Important Difference (MCID) for improvement were derived using the health anchor method and two distribution methods (Table 1). Thresholds for low, moderate and high disease activity were triangulated from established cut-off values for the patient global VAS, PASDAS and DAPSA.

Table 1. Minimal Clinically Important Difference (MCID) and Minimal detectable change (MDC)

\begin{tabular}{lcccc}
\hline & ANCHOR (MEDIAN) & DISTRIBUTION\#1 & DISTRIBUTION \#2 & MDC \\
\hline CPDAI & 0.5 & 1.49 & 1.5 & 4.16 \\
GRACE & 0.26 & 0.6 & 0.77 & 2.18 \\
PASDAS & 1.22 & 0.64 & 0.76 & 1.58 \\
DAS28 & 0.2 & 0.85 & 0.62 & 1.46 \\
3VAS & 1.13 & 1.16 & 0.91 & 3.12 \\
4VAS & 1.11 & 0.96 & 0.94 & 2.45 \\
DAPSA & 7.25 & 9.09 & 10.40 & 35.63 \\
\hline
\end{tabular}

Disease Activity Score for Psoriatic Arthritis (DAPSA); Psoriatic Arthritis Disease Activity Score (PASDAS); Composite Psoriatic Arthritis Disease Activity Index (CPDAI); Disease Activity Score 28 (DAS28). Distribution \#1: Baseline standard deviation (sd) * $\sqrt{ } 1-$ Cronbach's alphaDistribution \#2: $0.5 *$ baseline sdMinimal detectable change (MDC): $1.96 * 2{ }^{*} \mathrm{SEM}$ where SEM $=$ baseline $s d \sqrt{ } 1-$ ICC
Results: 139 subjects were recruited (59 male, 80 female, mean (range) age (years) 52.7 (19-83), mean (range) duration of psoriasis (years) $21.9(2-71)$, mean (range) duration of psoriatic arthritis (years) $6.1(0-41)$. Cut-off values for low, moderate and high disease activity were 1.3, 2.4, and 4.8 for the 3 Vas and 1.6, 2.8 and 5.0 for the 4 VAS (Figure 1). Estimates for the MCID and MDC for the continuous composite measures and are reported in Table 1.

Conclusion: We report estimates of clinically relevant improvements for continuous composite measures in PSA and estimates of low, moderate and high disease activity for the 3 and 4 VAS scales. The thresholds of meaning can now be tested in independent observational and clinical trial datasets.

\section{REFERENCES:}

[1] Coates et al 2018 A\&R Mar;70(3):345-355.

[2] Tillett $W$ et al $2021 \mathrm{~J}$ Rheum In Press

Figure 1: Thresholds of Meaning for the 3 and 4 VAS

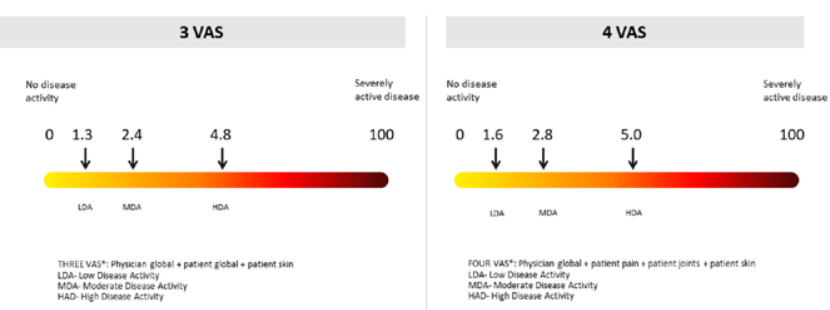

Acknowledgements Funding: This report is independent research funded by the National Institute for Health Research, Programme Grants for Applied Research [Early detection to improve outcome in patients with undiagnosed PsA ('PROMPT'), RP-PG-1212-20007]. The views expressed are those of the authors and not necessarily those of the NIHR or the Department of Health and Social Care.

Disclosure of Interests: William Tillett Speakers bureau: AbbVie, Amgen, Celgene, Lilly, Janssen, Novartis, MSD, Pfizer, and UCB, Consultant of: AbbVie BMS, Celgene, Lilly, Janssen, Novartis, Pfizer, and UCB, Grant/research support from: AbbVie, BMS, Janssen, Novartis, Pfizer, and UCB., Julia Day: None declared, Neil McHugh: None declared, Oliver FitzGerald Speakers bureau: AbbVie, BMS, Celgene, Lilly, Janssen, Novartis, Pfizer, and UCB, Consultant of AbbVie, BMS, Celgene, Lilly, Janssen, Novartis, Pfizer, and UCB, Grant/research support from: AbbVie, BMS, Janssen, Novartis, Pfizer, and UCB., Laura C Coates Speakers bureau: AbbVie, Amgen, Biogen, Celgene, Gilead, Eli Lilly, Janssen, Medac, Novartis, Pfizer, and UCB., Consultant of: AbbVie, Amgen, Boehringer Ingelheim, Bristol-Myers Squibb, Celgene, Eli Lilly, Gilead, Janssen, Novartis Pfizer, and UCB, Grant/research support from: AbbVie, Amgen, Celgene, Eli Lilly, Pfizer, and Novartis, Philip Helliwell: None declared DOI: 10.1136/annrheumdis-2021-eular.1622

\section{OP0225 \\ DEPRESSIVE SYMPTOMS IN PSA: A CROSS- SECTIONAL ANALYSIS FROM THE NATIONAL GERMAN RABBIT-SPA REGISTRY}

A. Regierer $^{1}$, A. Weiß ${ }^{1}$, M. Bohl-Buehler ${ }^{2}$, X. Baraliakos $^{3}$, F. Behrens ${ }^{4}$, G. Schett ${ }^{5}$, A. Strangfeld ${ }^{1} .{ }^{1}$ German Rheumatism Research Centre, Epidemiology Unit, Berlin, Germany; ${ }^{2}$ Rheumatology Practice, Rheumatology, Potsdam, Germany; ${ }^{3}$ Rheumazentrum Ruhrgebiet Herne, Ruhr-University, Bochum, Germany; ${ }^{4}$ Goethe University, Rheumatology and Fraunhofer Institute Translational Medicine and Pharmacology ITMP, Frankfurt, Germany; ${ }^{5}$ Friedrich Alexander University Erlangen-Nuremberg and Universitatsklinikum Erlangen, Department of Internal Medicine 3, Erlangen, Germany

Background: Psoriatic arthritis (PsA) is a chronic inflammatory disease affecting the musculoskeletal system as well as skin and nails. The prevalence of depression in psoriasis and PsA is high and ranges from $7-40 \%$ [1]. Persistent depressive mood may influence disease activity outcome in PsA, especially patient-reported outcomes.

Objectives: To assess the correlation of depressive symptoms with PsA-specific outcome parameters.

Methods: RABBIT-SpA is a prospective longitudinal cohort study including PsA patients enrolled at start of a new conventional treatment or b/tsDMARD treatment In regularly provided follow-up questionnaires, physician- and patient-reported information on the disease course including the depression screening tool WHO-5 to assess mental health is collected. For the current analysis, the WHO- 5 score was categorised into 4 groups using validated cut-offs: severe depressive symptoms $<13$, moderate depressive symptoms 13-28, mild depressive symptoms 29-50, well-being $>50$. Spearman correlation coefficient was calculated to analyse the relationship between the WHO- 5 score and various PsA related outcome parameters. Results: 936 PsA patients were included. Baseline characteristics are shown in Table 1. In 411 patients (43.9\%) the WHO-5 score indicated well-being, 249 